\title{
ESTRATEGIAS LEGALES PARA DETENER LA VIOLENCIA EN AGRAVIO DE LAS NIÑAS, NIÑOS Y ADOLESCENTES EN SU ENTORNO FAMILIAR
}

\section{LEGAL STRATEGIES TO STOP VIOLENCE TO THE TORT OF GIRLS, BOYS AND ADOLESCENTS IN THEIR FAMILY ENVIROMENT}

María Consuelo Barletta Villarán ${ }^{1}$ Pontificia Universidad Católica del Perú Lima, Perú https://orcid.org/0000-0001-8583-7309 mbarlet@pucp.edu.pe

\section{Resumen}

El presente estudio nos aproxima al conocimiento de las estrategias legales para detener la violencia de las niñas, niños y adolescentes por miembros de grupo familiar. Para dicho efecto se plantea una protección especial con diligencia reforzada para las intervenciones en tres supuestos: 1. Maltrato en la dinámica familiar bajo la potestad de crianza y disciplina, que no constituye hecho punible y es ejercida por los padres o representantes legales 2. Violencia contra las niñas, niños y adolescentes por un miembro de su entorno familiar que constituye delito y cuenta con representante legal protector/a 3. Violencia contra las niñas, niños y adolescentes por un miembro de su entorno familiar que constituye delito y no cuenta con un responsable protector/a.

Estas propuestas de intervención se basan en el reconocimiento de dos condiciones que enmarcan los actos de violencia en las niñas, niños y adolescentes, el primero referido a la situación de riesgo de no contar con cuidados parentales y el segundo a la desprotección familiar, ambos enmarcados en el Decreto Legislativo №1297 y su respectivo reglamento.

Para el análisis de los supuestos en mención se aplican tres principios pertinentes de la especialidad: La familia como institución fundamental para el desarrollo de las personas, el interés superior del niño y debida diligencia.

Palabras clave: Violencia, riesgo, desprotección familiar, protección judicial, protección social.

\section{Abstract}

This study brings us closer to the knowledge of legal strategies to stop violence against children and adolescents by members of the family group. For this purpose, a special

1 Abogada. Profesora Ordinaria de la Facultad de Derecho de la Pontificia Universidad Católica del Perú. Asociada Fundadora de COMETA 
protection with reinforced diligence is proposed for interventions in three cases: 1 . Abuse in family dynamics under the power of parenting and discipline, which does not constitute a punishable act and is exercised by parents or legal representatives 2. Violence against girls, boys and adolescents by a member of their family environment that constitutes a crime and has a protective legal representative 3. Violence against children and adolescents by a member of their family environment that constitutes a crime and does not have a responsible protector.

These intervention proposals are based on the recognition of two conditions that frame acts of violence in girls, boys and adolescents, the first referring to the risk situation of not having parental care and the second to the lack of family protection, both framed in Legislative Decree No. 1297 and its respective regulations.

For the analysis of the aforementioned assumptions, three pertinent principles of the specialty are applied: The family as a fundamental institution for the development of people, the best interests of the child and due diligence.

Keywords: Violence, risk, family vulnerability, judicial protection, social protection.

\section{A MODO DE INTRODUCCIÓN}

Resguardar a las niñas, niños y adolescentes de cualquier forma de violencia por parte de los integrantes de su grupo familiar, exige el establecimientoy consolidacióndeestrategiasdearticulacióninterinstitucional para su protección, las cuales son consignadas en procedimientos legalmente establecidos ${ }^{1}$.

Para dicho efecto, se proponen tres estrategias de intervención consistentes en la intervención frente al 1. Maltrato en la dinámica familiar bajo la potestad de crianza y disciplina, que no constituye hecho punible y es ejercida por los padres o representantes legales 2. Violencia contra las niñas, niños y adolescentes por un miembro de su entorno familiar que constituye delito y cuenta con representante legal protector/a 3. Violencia contra las niñas, niños y adolescentes por un miembro de su entorno familiar que constituye delito y no cuenta con un responsable protector/a.

Las estrategias han sido construidas considerando que las niñas, niños y adolescentes víctimas de violencia por miembros de su grupo familiar sólo

1 Ley №30403 (Publicada en el Diario Oficial “El Peruano", con fecha 30 de diciembre de 2015) y su reglamento D.S. № 003-2018-MIMP (Publicado en el Diario Oficial “El Peruano", con fecha 09 de junio de 2018), Decreto Supremo №004-2020-MIMP "Decreto Supremo que aprueba el Texto Único Ordenado de la Ley Nº 30364, Ley para Prevenir, Sancionar Y Erradicar la Violencia contra las Mujeres y los Integrantes del Grupo Familiar" (Publicado en el Diario Oficial “El Peruano, con fecha 06 de setiembre de 2020), el Decreto Legislativo №1297 (Publicado en el Diario Oficial "El Peruano", con fecha 30 de setiembre de 2016) y su reglamento D.S. №001-2018-MIMP(Publicado en el Diario Oficial "El Peruano", con fecha 10 de febrero de 2018). 
podrán encontrarse en dos condiciones: en riesgo por no contar con cuidados parentales o en desprotección familiar.

Estas propuestas de intervención deben ser aplicadas conforme a los principios jurídicos y enfoques que orientan la especialidad, y que han sido priorizados, ambos consignados en las normativas materia de análisis. De esta manera, los principios jurídicos resultan de especial relevancia para comprender el espíritu y esencia de cada estrategia, por dicho motivo resulta de utilidad y pertinencia que logremos su identificación y correlación con las propuestas planteadas.

Sobre el particular, en el Cuadro №1 podremos identificar los principios jurídicos recogidos en la temática y su vigencia en los distintos sistemas normativos.

\section{Cuadro № 1 : \\ Principios contenidos en la normativa sobre maltrato y violencia en agravio de los niños, niñas y adolescentes}

\begin{tabular}{|l|l|l|l|}
\hline \multirow{2}{*}{\multicolumn{1}{|c|}{ PRINCIPIO }} & \multicolumn{2}{c|}{ NORMATIVA QUE LO INCORPORA } \\
\cline { 2 - 4 } & $\begin{array}{c}\text { D.S. 003-2018- } \\
\text { MIMP } \\
\text { Ley No30403 }\end{array}$ & D.L. Na1297 & $\begin{array}{c}\text { D.S.No004- } \\
\text { 2020-MIMP }\end{array}$ \\
\hline Niño como sujeto de Derechos. & Artículo 6.c & & \\
\hline Interés Superior del Niño. & Artículo 6.a & Artículo 4.g & Artículo 2.2 \\
\hline Autodeterminación Progresiva & Artículo 6.d & & \\
\hline Participación & Artículo 6.e & & \\
\hline Igualdad y no Discriminación. & Artículo 6.b & Artículo 4.d & Artículo 2.1 \\
\hline $\begin{array}{l}\text { La familia como institución fundamental } \\
\text { para el desarrollo de las personas. }\end{array}$ & Artículo 6.f & Artículo 4.f & \\
\hline Debida Diligencia. & & Artículo 4.a & Artículo 2.3 \\
\hline Intervención inmediata y oportuna. & & & Artículo 2.4 \\
\hline Sencillez y Oralidad & & & Artículo 2.5 \\
\hline Razonabilidad y Proporcionalidad & & & Artículo 2.6 \\
\hline Especialidad y profesionalización & & Artículo 4.b & \\
\hline Excepcionalidad y temporalidad & & Artículo 4.c & \\
\hline Informalismo & & Artículo 4.e & \\
\hline Flexibilidad y gradualidad & & Artículo 4.h & \\
\hline Necesidad e idoneidad & & Artículo 4.i & \\
\hline Subsidiareidad progresiva & & & \\
\hline Fulo 4.j & \\
\hline
\end{tabular}

Fuente: Elaboración propia 
Las estrategias están planteadas para conseguir una intervención célere y eficaz, y el inmediato cese de la violencia. Considerando que todos los asuntos en que se involucran las niñas, niños y adolescentes deben ser tratados como problemas humanos ${ }^{2}$, es decir resaltar su derecho a una protección especial o reforzada, por su mayor vulnerabilidad.

A pesar de que todos los principios jurídicos resultan de interés para el análisis de la estrategia, por fines metodológicos y para la mayor comprensión de cada supuesto, se plantea detenernos en los siguientes principios jurídicos: La familia como institución fundamental para el desarrollo de las personas, el Interés Superior del Niño, Niña o Adolescente y la Debida Diligencia.

Así también, nos detenemos en los enfoques, en la medida que permiten conocer las cuestiones que son relevantes al diseñarse, interpretarse y aplicarse una estrategia de intervención.

\section{Cuadro No2:}

Enfoques contenidos en la normativa sobre maltrato y violencia en agravio de los niños, niñas y adolescentes

\begin{tabular}{|l|c|l|l|}
\hline \multirow{2}{*}{ ENFOQUE } & \multicolumn{3}{|c|}{ NORMATIVA QUE LO INCORPORA } \\
\cline { 2 - 4 } & $\begin{array}{c}\text { D.S.No003-2020 } \\
\text { Reglamento } \\
\text { Ley Na30403 }\end{array}$ & D.L. Na1297 & D.S.No004-2020 \\
\hline Ciclo de Vida & Artículo 5 a) & & Artículo 3.1 \\
\hline Cuso de la Vida & Artículo 5 b) & & \\
\hline Derechos & Artículo 5 c) & & Artículo 3.4 \\
\hline Género & Artículo 5 d) & & \\
\hline Interculturalidad & Artículo 5 e) & Artículo 4.k & Artículo 3.3 \\
\hline Equidad & Artículo 5 f) & & \\
\hline Discapacidad & Artículo 5 g) & & \\
\hline Integralidad & & & Artículo 3.2 \\
\hline Interseccionalidad & & & Artículo 3.5 \\
\hline Generacional & & & Artículo 3.6 \\
\hline
\end{tabular}

Fuente: Elaboración propia

Los enfoques nos direccionan al reconocimiento de la complejidad de la temática, puesto que nos sitúan frente a la vulnerabilidad como eje articulador: en la consideración de la niñez y adolescencia como etapas de desarrollo humano, a la continuidad del curso de la vida en su condición de víctima. Así también,

2 Artículo X del Título Preliminar del Código de los Niños y Adolescentes. 
en la condición de niña o adolescente mujer, de su pertenencia a una etnia o cultura, en su condición de discapacidad. El enfoque de interseccionalidad, que nos permite identificar y analizar todas estas condiciones que hacen a la víctima más vulnerable frente a su agresor/a. Se realiza este análisis para la consolidación de derechos y de equidad, pese a su situación de víctima.

\section{LA RESPONSABILIDAD ESTATAL}

El artículo 19 de la Convención sobre los Derechos del Niño refiere a la obligación de los Estados de adoptar todas medidas apropiadas para prevenir y erradicar la violencia en agravio de las niñas, niños y adolescentes, por dicho motivo la debida articulación de las distintas instituciones legalmente responsables resulta estratégico. Para dicho efecto, el Comité de Derechos del Niño, refiere que deberá implementarse un "sistema integrado, cohesivo, interdisciplinario y coordinado", sustentando en que si el sistema no cuenta con estas características tendrán efectos limitados.

Resulta igualmente estratégico y prioritario recoger la participación de las niñas, niños y adolescentes beneficiarios ${ }^{3}$ para la formulación, supervisión y evaluación de las mencionadas estrategias.

\subsection{MECANISMOS LEGALES DE CORRESPONSABILIDAD ESTATAL}

El Comité de Derechos del Niño refiere a que los Estados parte ratificantes de la Convención sobre los Derechos del Niño, conforme lo establecido en sus artículos 18 y 27, tienen la obligación de:

...apoyar y ayudar a los padres y otros cuidadores a proporcionar, dentro de sus posibilidades y medios económicos y en consonancia con la evolución de las facultades del niño, las condiciones de vida que sean necesarias para su desarrollo óptimo. ${ }^{4}$

De esta manera, se introduce el principio de mínima intervención estatal en la normativa internacional, cuestión que favorece a la implementación de medidas de protección social, a fin de fortalecer a la familia, para que asuma el cuidado y protección de la niña, niño o adolescente. Así también, es entendido por la Comisión Interamericana de Derechos Humanos cuando refiere a la obligación de los Estados de favorecer al desarrollo y la fortaleza de la familia a través de acciones que deriven

3 Párrafo 39 de la Observación General №13.

4 Fundamento 5 de la Observación General №13 del Comité de Derechos del Niño. 
en medidas de protección en favor del resguardo de derechos en el niño. ${ }^{5}$ En consecuencia, se demanda desarrollar políticas públicas, programas y servicios de apoyo y fortalecimiento direccionados a las familias, cuando éstas cuentan con determinadas competencias para constituirse en espacio protector de derechos en las niñas, niños o adolescentes.

El derecho priorizado es el "buen trato", se trata de un derecho específico que es expresión del derecho a la protección especial de las niñas, niños y adolescentes, y que legalmente implica "recibir cuidados, afecto, protección, socialización y educación no violentas, en un ambiente armonioso, solidario y afectivo, en el que se le brinde protección integral" ${ }^{\prime \prime}$, en todos los ámbitos en que se desenvuelven, sin exclusión alguna.

Sobre el particular, a fin de establecer la estrategia más idónea, se requiere iniciar con diferenciar los supuestos de "riesgo de no contar con cuidados parentales" y de "desprotección familiar".

\section{Cuadro №3}

Supuestos de niños, niñas y adolescentes en riesgo o desprotección familiar cuando son destinatarios/as de violencia física y/o psicológica o sexual ${ }^{6}$

\begin{tabular}{|c|c|}
\hline Tipos de Violencia & Categorías relevantes para clasificación \\
\hline \multirow[t]{2}{*}{$\begin{array}{l}\text { Violencia física y/o psi- } \\
\text { cológica }\end{array}$} & $\begin{array}{l}\text { En situación de riesgo } \\
\text { Cuando la familia de origen muestra interés por dejar de ejerc- } \\
\text { er violencia física o psicológica. }\end{array}$ \\
\hline & $\begin{array}{l}\text { En desprotección familiar } \\
\text { Cuando la familia de origen: } \\
\text { - Niega ocurrencia de los hechos. } \\
\text { - No denuncia a pesar de conocer. } \\
\text { - Nmenaza para evitar denuncia. } \\
\text { - Expulsa al agraviado/a. }\end{array}$ \\
\hline \multirow[t]{2}{*}{ Violencia sexual } & $\begin{array}{l}\text { En situación de riesgo } \\
\text { Familiar no agresor y responsable del NNA: } \\
\text { - } \quad \text { Hace la denuncia inmediatamente. } \\
\quad \text { Muestra interés por protección. }\end{array}$ \\
\hline & $\begin{array}{l}\text { En desprotección familiar } \\
\text { Familia de origen/cuidador principal: } \\
\text { - No denuncia a pesar de conocer. } \\
\text { - No muestra interés por brindar protección. } \\
\text { - El agresor vive en el entorno familiar. }\end{array}$ \\
\hline
\end{tabular}

Fuente: Elaboración propia

5 Ver UNICEF\& Comisión Interamericana de Derechos Humanos (2013). El Derecho del Niño y la Niña a la Familia. Cuidado alternativo poniendo fin a la institucionalización en las Américas.

6 Artículo 3A del Código de los Niños y Adolescentes, incorporado por la Ley №30403.

6 Supuestos recogidos de la Resolución Ministerial No065-2018-MIMP. Sin embargo la mencionada normativa refiere a todos las demás condiciones que originan la intervención del Estado por situación de riesgo o desprotección fami- 
En el cuadro $\mathrm{N}^{\circ} 3$ se realiza un resumen de las reacciones familiares ante la vulneración del derecho a la integridad de la niña, niño o adolescente por un miembro de entorno familiar, que han sido recogidos y detallados en la Resolución Ministerial 065-2018-MIMP, de manera complementaria al detalle de las características de los distintos actos de violencia. En los supuestos de riesgo podemos constatar la presencia de un miembro familiar responsable que contribuye a la adopción de medidas para que la violencia no se repita, mientras que en la desprotección familiar se evidencia que el entorno familiar es disfuncional para prodigar protección y cuidado, motivo por el cual, se justifica retirar a la niña, niño y adolescente de su familia de origen. A continuación, incorporamos las propuestas de articulación, que se constituyen en estrategias para erradicar la violencia en agravio delas niñas, niños o adolescentes por parte de un integrante del grupo familiar?

\section{Primera Estrategia: Maltrato en la dinámica familiar bajo la potestad de crianza y disciplina ejercida por los padres o representantes legales}

La primera estrategia contenida en elCuadro №4 proponela articulación de la Ley que prohíbe el Castigo Corporal y Trato Humillante en agravio de las niñas, niños y adolescentes (Ley №30403) y el Decreto Legislativo para la protección de las niñas, niños y adolescentes sin cuidados parentales o riesgo de perderlos (D.L.№1297), así como sus respectivos reglamentos ${ }^{8}$, en lo relativo a la situación de riesgo 9 por "Violencia física o psicológica en agravio de la niña, niño o adolescente, que no constituya una situación grave de acuerdo a la Tabla de Valoración de Riesgo"10. Este supuesto refiere a la mínima afectación a la integridad de los hijos/as, debido a la utilización de pautas no adecuadas de crianza, motivo por el cual queda en la intervención administrativa para su solución.

liar que son: violencia sexual en el ámbito familiar, explotación sexual de niños, niñas y adolescentes, violencia física en el ámbito familiar, violencia psicológica en el ámbito familiar, trabajo de niños, niñas y adolescentes en situación de calle o aquel que suponga afectación de derechos, vida en calle, mendicidad, negligencia o descuido, conductas de riesgo en la familia de origen, trata de niños, niñas y adolescentes y abandono.

7 Para los fines de este estudio, recogemos la clasificación de la familia en familia de origen y familia extensa, contenida en el artículo 3 del Decreto Legislativo №1297 “Decreto Legislativo para la protección de niñas, niños y adolescentes sin cuidados parentales o en riesgo de perderlos". (Publicado en el diario oficial "El Peruano" el 30 de diciembre de 2016), Distinguiéndose en base a la convivencia que mantiene la niña, niño o adolescente con los miembros que integran su entorno familiar y con quienes tiene un vínculo jurídico de parentesco.

8 Decreto Supremo 003-2018-MIMP y Decreto Supremo 001-2018-MIMP respectivamente.

9 Este supuesto refiere a la violencia física que la niña, niño o adolescente sufre de manera reiterada u ocasional, en cualquier parte de su cuerpo y que le causa dolor, por parte de uno o varios miembros de su familia de origen, a lo que se agrega la actitud familiar de prodigarlo como disciplina o castigo. Así también en la violencia psicológica se refiere a cualquier agresión verbal, gestual u humillante que no constituya hechos traumáticos.

10 Artículo 3.a del Decreto Supremo №001-2018-MIMP, Reglamento de la Ley №1297. 


\section{Cuadro №4 \\ Primera Estrategia \\ Maltrato en la dinámica familiar bajo la potestad de crianza y disciplina, que no constituye hecho punible y es ejercida por los padres o representantes legales}

Objetivo

Erradicar el maltrato del niño en su dinámica familiar mediante una estrategia de mínima intervención por mantener al niño en su propio hogar y prevenir una situación de desprotección familiar a futuro.

\section{Responsables}

Defensoría Municipal del Niño y Adolescente (Acreditada conforme D.L.1297)

Unidad de Protección Especial (UPE) del MIMP.

\section{\begin{tabular}{l|l}
\hline Etapa No1: Evaluación \\
\hline
\end{tabular}}

Diligencias y actuaciones para determinar factores de riesgo y de protección. (5 días)

Estrategia Estatal Declaración de riesgo y ordena elaboración del PTI.(1 día)

Etapa №2: Elaboración e implementación del PTI.

Información consignada en el PTI: Información de la niña, niño o

La niña, niño o adolescente, la familia de origen, el representante del Ministerio Público y los terceros con legítimo interés pueden activar el sistema. adolescente y de su familia de origen, identificación de los problemas que deben ser atendidos, medidas de protección y las acciones inmediatas a ejecutar. Su elaboración e implementación se encuentra a cargo de la DEMUNA u UPE, según sea el caso.

\section{Etapa №3: Seguimiento del PTI.}

Se registra y verifica el avance del PTI.

Se orienta las acciones para alcanzar los resultados.

Se puede variar la medida de protección inicialmente impuesta.

Se informa a la niña, niño o adolescente, y a la familia de origen sobre los avances.

\section{Medidas de Protección Social}

- Apoyo a la familia para fortalecer competencias de cuidado y crianza.

- Acceso a servicios de educación y salud para los niños.

- Acceso a servicios de atención especializada.

- Apoyo psicológico a favor del niño.

- Acceso a servicios para prevenir y abordar situaciones de violencia.

- Acceso a servicios de cuidado.

- Inclusión a programas sociales.

- Otras que fueran necesarias.

La niña, niño o adolescente puede solicitar la revocatoria de la medida de protección.

\section{Normativa Aplicable}

- Convención sobre los Derechos del Niño y el corpus juris internacional.

- Ley №27337 Código de los Niños y Adolescentes

- Ley №30403 “Ley que prohíbe el castigo físico y humillante contra los niños, niñas y adolescentes"

- Decreto Legislativo №1297 “Protección de los niños, niñas y adolescentes sin cuidados parentales o en riesgo de perderlos"

- $\quad$ Resolución Ministerial 065-2018-MIMP

Fuente: Elaboración propia 


\section{a. La familia como institución fundamental para el desarrollo de las personas}

En la Convención sobre los Derechos del Niño (CDN) se establece un doble requerimiento con la familia, por un lado respetar la orientación de los padres a sus hijos e hijas, en sus facultades de crianza, conforme lo establecido en los artículos 5 y 16 de esta normativa internacional y por otro lado, el Estado se hace como corresponsable con la familia, para garantizar la condición de sujeto de derechos de las niñas, niños y adolescentes en su propia dinámica familiar ${ }^{11}$.

Cuestión que es interpretada por el Comité de Derechos del Niño, al señalarse que:

...reconoce la importancia primordial de la familia, incluida la familia extensa, en la atención y protección del niño y en la prevención de la violencia. Sin embargo, reconoce también que la mayor parte de los actos de violencia se producen en el ámbito familiar y que, por consiguiente, es preciso adoptar medidas de intervención y apoyo cuando los niños sean víctimas de las dificultades y penurias sufridas o generadas en las familias. ${ }^{12}$

La primera estrategia refiere al supuesto que los padres no cuenten con competencias parentales que favorezcan a la crianza positiva de sus hijos/as y por lo tanto, afectan su desarrollo integral por no brindarles un ambiente de protección libre de violencia, esto debido a que culturalmente se encuentra muy arraiga la confusión entre disciplina y maltrato. Sobre el particular, el Comité de Derechos del Niño ha venido pronunciándose en el requerimiento de erradicar todo tipo de violencia en agravio de las niñas, niños o adolescentes, no debiendo existir ninguna práctica socialmente tolerada o legalmente autorizada en el rol educativo de los padres y por lo

11 En la legislación peruana, esta relevancia jurídica y social otorgada a la institución familiar es recogida en el artículo 4 de la Constitución Política y en base a ello, el artículo 233 del Código Civil incide en la necesidad de su consolidación y fortalecimiento; sobre el particular, el Estado peruano ha promulgado la Ley de Fortalecimiento de la Familia (Ley №28542 “Ley de Fortalecimiento de la Familia". Publicada en el Diario Oficial "El Peruano", el 27 de mayo de 2005), que al definir su objetivo en el artículo 1, indica: “...promover y fortalecer el desarrollo de la familia como fundamento de la sociedad y espacio fundamental para el desarrollo integral del ser humano, basándose en el respeto de los derechos fundamentales y las relaciones equitativas entre sus miembros...". Así también, en relación al resguardo de la institución familiar como espacio protector para las niñas, niños y adolescentes, identificamos algunos artículos que resultan de vital importancia, como el artículo VI del Título Preliminar del Código de los Niños y Adolescentes, que señala que "la obligación de atención al niño y al adolescente se extiende a la madre y a la familia del mismo". Así también, el artículo 8 del mencionado cuerpo legislativo refiere al derecho a vivir, crecer y desarrollarse en el seno de su familia, sin desconocer diversos supuestos que implican carecer de ésta o no constituirse ésta en un espacio protector. Ambas situaciones facultan al Estado a intervenir separándolos, con la exclusiva finalidad de brindarles protección.

12 Observación General №13 “Derecho el niño a no ser objeto de ninguna forma de violencia” CRC/C/GC/13 del 18 de abril del 2011. 
tanto se hizo necesario erradicar la tolerancia legal frente al "castigo físico"13 y el "trato humillante" como mecanismos de "corrección moderada"14, a pesar de no constituir hechos punibles, tal y como lo señala explícitamente la Ley №30403. Sin embargo, es necesario destacar que el propio Comité ha sido explícito en señalar que esto no implica negar la autoridad parental para ejercer disciplina sobre los hijos e hijas.

En base a ello, en esta estrategia se recoge un carácter de mínima funcionalidad a la dinámica familiar, en la medida que la niña, niño o adolescente maltratada/o cuenta con un aliado en este entorno, el cual coadyuvará a poner término a los episodios de violencia en su agravio. Corresponde entonces que el Estado brindar soporte a la familia para constituirse en un espacio funcional para garantizar el desarrollo integral de sus miembros, esto se encuentra sustentado en los artículos 3.2 y 27.3 de la Convención sobre los Derechos del Niño.

En consecuencia, declarar la situación de riesgo de la niña, niño o adolescente implica la intervención del Estado para restituir a las niñas, niños y adolescentes su derecho a vivir, crecer y desarrollarse en una familia funcional, el cual se ha visto afectado por la utilización del castigo físico o trato humillante en la dinámica de disciplina de los hijos e hijas.

\section{b. Interés Superior del Niño ${ }^{15}$}

\section{Conforme lo señalado por el Tribunal Constitucional ${ }^{16}$ se requiere} la adopción de medidas concretas, lo que será materia de análisis en cada estrategia compartida.

13 En la Observación General Nª del Comité de Derechos del Niño se define el castigo "corporal" o "físico", que consiste en utilizar: "...la fuerza física y que tenga por objeto causar cierto grado de dolor o malestar, aunque sea leve. En la mayoría de los casos se trata de pegar a los niños ("manotazos", "bofetadas", "palizas"), con la mano o con algún objeto - azote, vara, cinturón, zapato, cuchara de madera, etc. Pero también puede consistir por ejemplo en dar puntapiés, zarandear o empujar a los niños, arañarlos, pellizcarlos, morderlos, tirarles del pelo o de las orejas, golpearlos con un palo, obligarlos a ponerse en posturas incómodas, producirles quemaduras, obligarlos a ingerir alimentos hirviendo u otros productos."

14 En ambos casos se reconoce un elemento objetivo, que consiste en los hechos que constituyen una afectación al buen trato y un elemento subjetivo, referido a la intención de modificar, controlar o cambiar el comportamiento de las niñas, niños y adolescentes.

15 En la actualidad, se ha logrado orientar su naturaleza jurídica hacia una ponderación de derechos. Esto es fácilmente constatable al dar lectura a la distinta normativa de la especialidad (Artículo 8.3 del Decreto Supremo №002-2018MIMP, Reglamento de la Ley N30466), en que se alude explícitamente a este mecanismo y se indica: “...un adecuado análisis de la relación de preferencia entre los derechos que entran en conflicto. Cuando se trata de la propia niña, niño o adolescente, se prefiere aquellos que garanticen a largo plazo su interés y desarrollo de manera integral. Tratándose de un grupo de niñas, niños o adolescentes, se analizan los intereses de las partes, caso por caso, para encontrar una solución adecuada; lo mismo se hace si entran en conflicto los derechos de otras personas con el interés superior del niño." En realidad, esta resolución de conflictos ha sido planteada desde la propia Convención sobre los Derechos del Niño, cuando el artículo 9.1 autoriza a que el Estado separe al niño de sus padres, cuestión que procede cuando al ponderar derechos se privilegia sus derechos a la integridad y al desarrollo integral, en aras del resguardo de su derecho a la consideración de su interés superior.

16 Sentencia del Tribunal Constitucional. Expediente Nª4509-2011-PA/TC. 
Juicio de Idoneidad (Adecuación): ¿La estrategia implementada produce el cese de la violencia mediante el fortalecimiento de la familia como espacio protector y funcional para el niño, niña o adolescente?

Juicio de Necesidad: ¿La estrategia implementada constituye una mínima intervención de injerencia estatal en la vida privada y familiar del niño/a o adolescente?.

Juicio de Proporcionalidad: ¿La estrategia implementada implica la adopción de medidas de protección social razonables y proporcionadas a la vulneración del derecho a la integridad?.

Dar respuesta a estas preguntas contribuirá a la motivación del interés superior de la niña, niño o adolescente por la autoridad que resuelva en cada caso concreto y así también a cumplir con el principio de razonabilidad y proporcionalidad.

Así también, es fundamental escuchar la opinión de los beneficiarios / as de la intervención, puesto que involucrarlos/as garantiza a la adopción de medidas acordes a su interés superior.

\section{c. Debida diligencia}

La actuación del Estado con la debida diligencia implica una serie de acciones que garantizan el resultado planteado por la normativa, prioritariamente consistente en producir el cese de la violencia sin necesidad de retirar al niño, niña o adolescente de su propio entorno familiar.

Además de la celeridad como exigencia común en todas las estrategias, se hace necesario verificar que los agentes actuaron con cuidado, eficacia y responsabilidad, lo cual implicará lo siguiente:

1. Evaluación: En esta etapa corresponde verificar que los factores de riesgo y de protección no justifican el retiro del niño, niña o adolescente de su entorno familiar, y que el plan de tratamiento individual tendrá como objetivo prioritario el fortalecimiento de la dinámica familiar como espacio protector. En consecuencia, evaluaciones parciales o sesgadas, que originan intervenciones en exceso o desproporcionadas, impactan en la vulneración del derecho de las niñas, niños y adolescentes a vivir, crecer y desarrollarse en una familia. 
2. Elaboración e Implementación del Plan de Tratamiento Individual: En esta etapa será necesario determinar medidas de protección sociales que contribuyan al diseño e implementación de una estrategia interinstitucional para la superación de los factores de riesgo y el fortalecimiento de las medidas de protección, teniéndose en cuenta prioritariamente su necesidad e idoneidad. Si contrariamente, los objetivos de la intervención no responden a los requerimientos y demandas de intervención del caso concreto, se mantiene el riesgo que la situación de violencia se agrave y la niña, niño o adolescente devenga en una situación de desprotección familiar.

3. Seguimiento del Plan de Tratamiento Individual: En esta etapa se hace necesario conocer el impacto de la estrategia, el seguimiento resulta fundamental para ajustar la intervención, autorizándose a la instancia administrativa proceder a la variación que corresponda, esto permitirá que la reacción se ajuste a los requerimientos de las niñas, niños y adolescentes, en base a ello rige el principio de flexibilidad. De lo contrario, las medidas de protección impuestas pueden no favorecer al cese del maltrato, quedando en riesgo de seguir padeciendo actos de violencia.

Por último, se hace necesario destacar que el "castigo físico" y "trato humillante" no constituyen delitos, pero su práctica podría acarrearlos; así también, la detección de estos mecanismos de disciplina podrían ir aparejados del reconocimiento de una situación de desprotección familiar. Motivo, por el cual no es posible relacionar de manera univoca el "castigo físico" o el "trato humillante" con riesgo o desprotección, dependerá del análisis del caso en concreto.

\section{Segunda Estrategia: Violencia contra las niñas, niños y adolescentes por un miembro de su entorno familiar que constituye delito y cuenta con representante legal protector/a.}

Esta estrategia refiere a la articulación del Texto Único Ordenado de la Ley para prevenir, sancionar y erradicar la violencia contra las mujeres y los integrantes del grupo familiar (D.S. 004-2020-MIMP) y el Decreto Legislativo para la protección de las niñas, niños y adolescentes sin cuidados parentales o riesgo de perderlos (D.L. №1297), en lo relativo a las niñas, niños y adolescentes que se encuentran en una situación de riesgo por el supuesto "Violencia física o psicológica en agravio de la niña, niño o adolescente, que no constituya una situación grave de acuerdo a la Tabla de Valoración de Riesgo". 
Refiere a un supuesto que implica la comisión del delito de violencia contra la niña, niño o adolescente por parte de los integrantes de su grupo familiar basándose en una relación de confianza u autoridad, resultando ejecutable el proceso de tutela urgente (D.S. 004-2020-MIMP) y aplicables las medidas de protección de naturaleza autosatisfactivas, por regir el principio precautorio, en la medida que bastará con demostrar la existencia de indicios suficientes y razonables para determinar su procedencia ${ }^{17}$. Adicionalmente, de manera conjunta con las medidas de protección se deberá evaluar la aplicación de las medidas cautelares al caso concreto, las cuales deben ser parte de la estrategia de intervención, y ambas tendrán vigencia mientras persistan en la niña, niño o adolescente, las condiciones de riesgo de volver a sufrir un acto de violencia. Asimismo, de manera conjunta serán aplicables las medidas de protección social por su situación de riesgo, a fin de fortalecer o afianzar la dinámica familiar, que favoreciera al delito en agravio de la niña, niño o adolescente.

17 Artículo 32 del Decreto Supremo №004-2020-MIMP, Texto Único Ordenado de la Ley №30364 “Ley para prevenir, sancionar y erradicar la violencia contra las mujeres". 


\section{Cuadro №5 \\ Segunda Estrategia \\ Violencia contra las niñas, niños y adolescentes por un miembro de su entorno familiar que constituye delito y cuenta con representante legal protector/a \\ Objetivo}

Brindar protección a la niña, niño o adolescente para el cese de la violencia prodigada por parte de un miembro de su entorno familiar y fortalecer a la familia.

\section{Aliados directos}

Policía Nacional del Perú / Juzgado de Familia / Juzgado Penal

Defensoría Municipal del Niño y Adolescente (Acreditada conforme D.L.1297)

Unidad de Protección Especial (UPE) del MIMP.

\begin{tabular}{|c|c|c|}
\hline \multirow[t]{2}{*}{$\begin{array}{l}\text { Estrategia } \\
\text { Estatal }\end{array}$} & \multicolumn{2}{|c|}{$\begin{array}{l}\text { Etapa №1: Evaluación del riesgo } \\
\text { La policía (o en su caso el juzgado de familia) aplica la ficha de evaluación } \\
\text { del riesgo. Notifica a la Fiscalía de Familia. Pone en conocimiento del juzga- } \\
\text { do de familia los resultados: riesgo leve o moderado, severo o no se puede } \\
\text { determinar. (D.S. №004-2020) }\end{array}$} \\
\hline & \multicolumn{2}{|c|}{$\begin{array}{l}\text { Etapa No2: Adopción y Seguimiento de la Medida de Protección. } \\
\text { El juez de familia al conocer (o luego de realizar) la evaluación del riesgo } \\
\text { los resultados de la situación de vulnerabilidad de la niña, niño o adoles- } \\
\text { cente dictará la medida de protección judicial y la(s) medida(s) cautelar(es) } \\
\text { El seguimiento está a cargo de la policía nacional o del equipo multidis- } \\
\text { ciplinario (D.S. №004-2020) }\end{array}$} \\
\hline \multirow{2}{*}{$\begin{array}{l}\text { La policía } \\
\text { recepciona } \\
\text { la denuncia } \\
\text { verbal o por } \\
\text { escrito de la } \\
\text { niña, niño o } \\
\text { adolescente o } \\
\text { de cualquier } \\
\text { persona que } \\
\text { tenga conoci- } \\
\text { miento. }\end{array}$} & \multicolumn{2}{|c|}{$\begin{array}{l}\text { Etapa №3: Derivación a la UPE por parte del juez de familia. } \\
\text { Etapas №1, } 2 \text { y } 3 \text { del Cuadro №4 (simultánea a la Etapa №2) }\end{array}$} \\
\hline & \multicolumn{2}{|c|}{$\begin{array}{l}\text { Etapa No4: Proceso penal por el delito de violencia por integrante de } \\
\text { grupo familiar. } \\
\text { El juez penal al emitir sentencia deberá pronunciarse sobre. } 1 \text {. La continuidac } \\
\text { o modificación de las medidas de protección. } 2 \text {. El tratamiento terapéutico a } \\
\text { favor de la víctima. } 3 \text {. El tratamiento especializado al condenado. } 4 \text {. La conti } \\
\text { nuidad o modificación de las medidas cautelares } 5 \text {. La inscripción de la sen } \\
\text { tencia en el Registro Único de Víctimas y Agresores por Violencia contra la } \\
\text { Mujeres y los Integrantes del Grupo Familiar, entre otras. (D.S. NNo04-2020) }\end{array}$} \\
\hline \multicolumn{2}{|c|}{ Medidas de Protección Social y Judicial } & \\
\hline \multicolumn{2}{|c|}{$\begin{array}{l}\text { - } \quad \text { Retiro del Agresor del domicilio. } \\
\text { - } \quad \text { Impedimento de acercamiento. } \\
\text { - } \quad \text { Tratamiento psicológico, u otras. } \\
\text { Complementariamente las medidas de } \\
\text { protección social del Cuadro No4. }\end{array}$} & \\
\hline \multicolumn{3}{|c|}{ Normativa aplicable Aplicable } \\
\hline \multicolumn{3}{|c|}{$\begin{array}{l}\text { Convención sobre los Derechos del Niño y el corpus juris internacional/ Ley №27337 - Có- } \\
\text { digo de los Niños y Adolescentes / Decreto Supremo 004-2020-MIMP/ Decreto Legislativo } \\
\text { NNo1297 “Protección de los niños, niñas y adolescentes sin cuidados parentales o en riesgo } \\
\text { de perderlos" / Resolución Ministerial 065-2018-MIMP. }\end{array}$} \\
\hline
\end{tabular}

Fuente: Elaboración propia 
A continuación, procedemos al análisis de la segunda estrategia en base a los principios jurídicos priorizados:

\section{a. La familia como institución fundamental para el desarrollo de las personas}

En esta estrategia al igual que la primera, se considera la mantención de la niña, niño o adolescente en su familia. Se destaca la presencia de algún familiar que pueda contribuir a brindar protección frente al contexto violento. En este supuesto se refuerzan las medidas de protección sociales a fin de contribuir a desarrollar competencias parentales a los responsables cuidadores, y que éstos se constituyan en aliados para prevenir cualquier acto de violencia futura.

Sin embargo, la normativa faculta al juez especializado para dictar establecer un acogimiento familiar como medida cautelar, y se olvida a la institución civil de la "tutela", cuya aplicación correspondería cuando hay familia extensa y se afectado el ejercicio de la patria potestad (suspensión o pérdida). Sobre el particular, la "tutela" es una institución obligatoria para los miembros de la familia extensa de la niña, niño o adolescente y otorga representación legal. Mientras que, el acogimiento familiar no otorga la representación legal y deberá procederse a su ratificación mediante la intervención de la UPE.

\section{b. Interés Superior del Niño}

En la adopción de medidas concretas para el resguardo de la integridad de los niños, niñas y adolescentes, la consideración del interés superior del niño como derecho, principio y norma de procedimiento, nos orienta en el siguiente análisis:

Juicio de Idoneidad (Adecuación): ¿La estrategia implementada produce el cese de la violencia con acciones judiciales sobre el sujeto agresor? ¿la estrategia implementada contribuye al fortalecimiento de la familia, como espacio protector y funcional para el niño, niña o adolescente?

Juicio de Necesidad: ¿La estrategia implementada se ajusta a la evaluación del riesgo, resultando (leve, moderado o severo) de que el niño, niña o adolescente se vuelva a constituir en víctima?

Juicio de Proporcionalidad: ¿La estrategia implementada constituye una mínima intervención en la vida privada y familiar del niño/a o adolescente? 
¿La estrategia implementada implica la adopción de medidas de judiciales y de protección social razonables y proporcionables al caso?

Dar respuesta a estas preguntas favorece a la consideración del interés superior del niño, niña y adolescente como una prioridad y contribuye a la motivación de su aplicación en cada caso concreto.

\section{c. Debida diligencia}

Dando continuidad al análisis de la debida diligencia en esta estrategia, se hace necesario detenernos en las distintas etapas que constituyen la intervención. Debiendo primero, reconocer la naturaleza jurídica del proceso de tutela urgente, éste es distinto al proceso ordinario (demanda, contestación de demanda, audiencias), a fin de priorizar la celeridad en la adopción de las medidas de protección judiciales ${ }^{18}$.

\section{Evaluación del Riesgo}

Debe reconocerse capacidad al niño, niña o adolescente para realizar la denuncia, por ningún motivo podrá desestimarse o minimizarse su relato sobre la agresión familiar sufrida.

Adicionalmente, la evaluación del riesgo implica objetividad al realizarse. Es necesario que el responsable del llenado de la ficha no interprete o califique según su propio criterio; en consecuencia, la niña, niño o adolescente deberá participar en la calificación de los hechos y en la obtención del resultado de medición, en la medida que se constituye en el principal informante de los hechos que sucedieron en su agravio.

La derivación al juzgado con la información respectiva sobre la valoración del riesgo podría demorar de 24 a 72 horas $^{19}$, por dicho motivo resulta fundamental, lograr la articulación con la fiscalía penal para que se cumpla con el principio de celeridad e inmediatez, evitando formalismos que podrían en grave riesgo la integridad o vida de la niña, niño o adolescente.

18 Derecho a la defensa que podría hacer regir en el proceso penal o al apelar la medida de protección impuesta.

19 Sin embargo, el D.L. №1470 “Decreto Legislativo que establece medidas para garantizar la atención y protección de las víctimas de violencia contra las mujeres y los integrantes del grupo familiar durante la Emergencia Sanitaria declarada por el Covid-19", determina que se califique en 24 horas y se utilicen recursos tecnológicos para medir el riesgo de la víctima de volver a sufrir violencia. 


\section{Adopción y seguimiento de la medida de protección:}

La adopción de las medidas de protección judiciales son parte de la estrategia del proceso integral del D.S. №004-2020-MIMP, esto refiere al requerimiento de información y articulación entre el juzgado especializado y el juzgado penal, por tratarse de un proceso integral, a fin de conocer sobre la aplicación, seguimiento y efectividad de las medidas de protección y coercitivas. Sin embargo, existe autonomía entre ambos procesos, puesto que el resultado a favor del supuesto agresor en la vía penal deberá evaluarse en audiencia por el juzgado especializado, para modificar o dejar sin efecto las medidas de protección.

Adicionalmente, el seguimiento de las medidas de protección se constituye en el gran reto o cuestión de prioritaria importancia, puesto que las medidas de protección tienen como finalidad el cese de la violencia y por dicha razón, el juez del ámbito de protección se encuentra autorizado a actuar en base a un principio precautorio, puesto que bastará la identificación de suficientes y razonables indicios (recogidos en la evaluación del riesgo), para que proceda su otorgamiento.

Asimismo, en base al principio de oficiosidad, el juzgado especializado de protección podrá de oficio, modificar, ampliar o dejar sin efecto las medidas de protección ${ }^{20}$, (aunque también procede a solicitud de parte). Para adoptar estas decisiones, resulta estratégico involucrar no sólo a la policía sino también a los equipos multidisciplinarios de los juzgados para que contribuyan al seguimiento personalizado de los niños, niñas y adolescentes, así también la normativa se coloca en el supuesto que la corte no cuente con este equipo, buscándose involucrar a otros actores ${ }^{21}$. Sin embargo, la sobrecarga de funciones de los equipos multidisciplinarios y la insuficiencia en el reforzamiento de las instituciones supletorias por ley, serán un obstáculo para prodigar una protección reforzada a los niños, niñas y adolescentes.

Otra cuestión de importancia es la adopción de medidas cautelares que contribuyan a la consecución del objetivo de la medida de protección.

20 Artículo 35 del D.S. №04.2020-MIMP, Texto Único Ordenado de la Ley №30364 “Ley para prevenir, sancionar y erradicar la violencia contra las mujeres".

21 Tal y como ha sido establecido en el artículo 37 del D.S. №004-2020-MIMP, colocándose también en el supuesto que no existan equipos multidisciplinarios en la Corte Superior de Justicia de un distrito judicial, cuestión que origina el involucramiento de "...los centros de salud mental comunitarios, hospitales, defensorías municipales de niños, niñas y adolescentes (DEMUNA), centros emergencia mujer, Programa Integral Nacional para el Bienestar Familiar (INABIF), Estrategia Rural o gobiernos locales, de acuerdo a sus competencias", al haberle delegado el juzgado de familia esta función de supervisión. 
Esto es fácilmente verificable cuando se adopta la medida de protección de retiro del agresor del entorno familiar y asimismo el impedimento de acercamiento al niño, niña o adolescente, a pesar de tener un vínculo filial con éste, cuestión que ocasiona la adaptación simultánea y célere de medidas cautelares de suspensión de la patria potestad, tenencia y régimen de visitas. Esto resulta crucial para proteger a los niños, niñas y adolescentes, puesto que la inafectación de las instituciones familiares, podrían ponerlos en riesgo frente a su padre/madre que comparte la condición de agresor/a.

\section{Derivación a la UPE por parte del juzgado de familia}

En simultáneo a la segunda etapa, en todos los supuestos de violencia en agravio de las niñas, niños y adolescentes corresponderá reforzar las medidas de protección, calificando los casos como "situación de riesgo" o "desprotección familiar".

Las medidas de protección sociales adoptadas en esta etapa, deberán ser complementarias a las judiciales, mediante la articulación de la instancia judicial con la entidad administrativa (DEMUNA o UPE), a fin de conseguir el fortalecimiento y funcionalidad familiar para seguirse haciendo cargo de la niña, niño o adolescente. Este componente de la estrategia resulta crucial, puesto se le mantiene con su familia, pese haber sido víctima de delito, sin desconocerse que se hace necesario revertir los factores de riesgos, todavía existentes, y así contribuir a la prevención de futuros actos de violencia. De esta manera, deberá considerarse que las decisiones en torno a las medidas de protección, deberán considerar primordialmente el interés superior de la niña, niño o adolescente y la obligación estatal de una diligencia reforzada.

Será la UPE la entidad encargada de su calificación conforme lo explicado en el Cuadro №4, y procederá a su derivación a una DEMUNA acreditada para la implementación de las medidas de protección sociales pertinentes y su respectivo seguimiento.

En consecuencia, en esta estrategia la condición sociofamiliar de la niña, niño o adolescente no justifica retirarlo de su entorno familiar. Sin embargo, se corre el riesgo de evaluaciones parciales o sesgadas, que contribuyan a intervenciones en exceso o desproporcionadas, limitando el ejercicio del derecho a vivir, crecer y desarrollarse en la familia. 


\section{Proceso penal por el delito de violencia por integrante del grupo familiar.}

En esta etapa se despliegan todos los medios probatorios para atribuir la autoría al supuesto agresor, intervención que corresponde a la fiscalía penal para desvirtuar la presunción de inocencia y por su lado, la defensa ofrecerá los medios probatorios que favorezcan a la absolución.

Así también, el juez penal tendrá que manifestarse sobre la condición procesal: internamiento preventivo o comparecencia, lo fundamental es conseguir que las decisiones estén debidamente articuladas entre el ámbito de protección y el penal. De esta manera, en caso se variara la medida coercitiva de internamiento preventivo o se determinará la comparecencia, la niña, niño o adolescente deberá estar suficientemente resguardado de cualquier acto de agresión coexistente o posterior al proceso mediante estratégicas medidas de protección.

\subsection{MECANISMOS LEGALES DE RESPONSABILIDAD ESTATAL SUBSIDIARIA}

El Estado en su rol subsidiario a la familia asume una función tutelar, ante la ausencia o disfuncionalidad de la familia de origen y extensa como espacio protector. Su intromisión en el ámbito familiar se manifiesta al extremo de encontrarse legitimado del retiro de las niñas, niños y adolescentes de su propio entorno familiar. Sin embargo, su intervención debe ser concebida como extrema y temporal, por el nivel de afectación que acarrea.

Sobre el particular, el artículo 20 de la Convención de los Derechos del Niño refiere a que los niños temporal o permanentemente privados de su medio familiar, o cuyo superior interés exija que no permanezcan en ese medio, tendrán derecho a la protección y asistencia especiales del Estado, en base a su interés superior. ${ }^{22}$

En la evaluación de cada caso, tendrá que verificarse la probabilidad de la niña, niño o adolescente de mantener un vínculo con su familia de origen y por lo tanto, de hacer partícipe a ésta de la estrategia de intervención, de esa manera se resguarda su derecho a mantener relaciones personales con su familia, siempre y cuando le sea beneficioso, aún cuando se requiriera su retiro a un acogimiento familiar o residencial.

22 Artículo 3 del Decreto Legislativo №1297. 
Tercera Estrategia: Violencia contra las niñas, niños y adolescentes por un miembro de su entorno familiar que constituye delito y no cuenta con un responsable protector/a.

En esta estrategia articulamos la aplicación del Decreto Supremo №0042020-MIMP con el Decreto Supremo №1297 en lo relativo a la desprotección familiar, que alude a la amenaza o afectación grave a la integridad física de la niña, niño o adolescente, ${ }^{23}$ cuando se produzca violencia sexual o violencia física o psicológica por parte de los miembros de su familia de origen y éstos lo consintieran o actuaran de manera negligente ${ }^{24}$.

En el análisis de la naturaleza jurídica de ambas estrategias de protección judicial, es verificable que el D.S. №004-2020-MIMP se encuentra sesgado a la protección prioritaria a la mujer, motivo por el cual resulta estratégico, afianzar la protección especial, específica y adicional a prodigarse a las niñas, niños y adolescentes víctimas de violencia, conforme el artículo 4 de la Constitución Política del Perú, al aplicarse complementariamente las medidas de protección del D.L. №1297.

Por este motivo las medidas de protección se deben caracterizar por ser una respuesta adecuada, oportuna, integral y ejecutable, a fin que cumplan una función preventiva, neutralizadora y de recuperación a las niñas, niños $\mathrm{y}$ adolescentes. 


\section{Cuadro №6 \\ Tercera Estrategia \\ Violencia contra las niñas, niños y adolescentes por un miembro de su entorno familiar que constituye delito y no cuenta con un responsable}

protector/a.

\section{Objetivo}

Brindar protección a la niña, niño o adolescente para el cese de la violencia prodigada por parte de su familia de origen y para separarlo de ésta.

\section{Aliados directos}

Policía Nacional del Perú/ Juzgado de Familia / Juzgado Penal

Unidad de Protección Especial (UPE) del MIMP.

\begin{tabular}{|c|c|c|}
\hline \multirow[t]{3}{*}{ Estrategia Estatal } & \multicolumn{2}{|c|}{$\begin{array}{l}\text { Etapas №1, } 2 \text { y } 4 \text { del Cuadro N } \mathbf{5} 5 \text { (D.S. 004-2020- MIMP) } \\
\text { Corresponderá que el juez de familia aplicar el acogimiento familiar } \\
\text { como medida cautelar o el internamiento en albergue como medida } \\
\text { de protección. }\end{array}$} \\
\hline & \multicolumn{2}{|c|}{$\begin{array}{l}\text { Etapa No4: Evaluación sociofamiliar por la UPE (D.L. №1297) } \\
\text { - Diligencias y actuaciones para determinar factores de riesgo y de } \\
\text { protección. } \\
\text { - Declaración de desprotección familiar provisional y medida de pro- } \\
\text { tección aplicable. }\end{array}$} \\
\hline & \multirow{2}{*}{\multicolumn{2}{|c|}{$\begin{array}{l}\text { Etapa No5: Pronunciamiento judicial sobre la Desprotección Fami- } \\
\text { liar (D.L. No1297) } \\
\text { - Juez aprueba la declaración de desprotección familiar provisional y } \\
\text { la medida de desprotección. } \\
\text { - Juez aprueba la declaración de desprotección familiar provisional y } \\
\text { varia la medida de protección. } \\
\text { - Juez desaprueba la declaración de desprotección familiar provisio- } \\
\text { nal y archiva el caso o deriva a situación de riesgo para implementa- } \\
\text { ción de Etapas №2 y } 3 \text { del Cuadro № }{ }^{\circ} \text {. } \\
\text { - Juez inicia proceso para desprotección familiar permanente y eva- } \\
\text { luación de la adoptabilidad. }\end{array}$}} \\
\hline $\begin{array}{l}\text { La niña, niño o } \\
\text { adolescente, la fa- } \\
\text { milia de origen, el } \\
\text { representante del } \\
\text { Ministerio Públi- } \\
\text { co y los terceros } \\
\text { con legítimo inte- } \\
\text { rés pueden acti- } \\
\text { var el sistema. }\end{array}$ & & \\
\hline \multicolumn{2}{|c|}{ Medidas de Protección Judicial } & Medidas Cautelares \\
\hline \multicolumn{2}{|c|}{$\begin{array}{l}\text { En la Etapa №2 cuadro №5 } \\
\text { Impedimento de acercamiento. } \\
\text { Suspensión temporal de visitas. } \\
\text { En la Etapa №4 } \\
\text { Acogimiento familiar (familia extensa, tercero } \\
\text { o especializado) } \\
\text { Acogimiento Residencial. } \\
\text { Adopción. } \\
\text { Entre otras. }\end{array}$} & $\begin{array}{l}\text { - } \text { Alimentos. } \\
\text { - } \quad \text { Regímenes de visitas. } \\
\text { Suspensión o extinción de la } \\
\text { patria potestad. } \\
\text { Se informa a la víctima sobre su derecho } \\
\text { de iniciar el proceso sobre las materias. }\end{array}$ \\
\hline \multicolumn{3}{|c|}{ Normativa aplicable Aplicable } \\
\hline \multicolumn{3}{|c|}{$\begin{array}{l}\text { Convención sobre los Derechos del Niño y el corpus juris internacional. } \\
\text { Ley №27337 - Código de los Niños y Adolescentes / Decreto Supremo 004-2020-MIMP / } \\
\text { Decreto Legislativo NNo1297 “Protección de los niños, niñas y adolescentes sin cuidados } \\
\text { parentales o en riesgo de perderlos" / Resolución Ministerial 065-2018-MIMP }\end{array}$} \\
\hline
\end{tabular}

Fuente: Elaboración propia 


\section{a. La familia como institución fundamental para el desarrollo de las personas}

En el cuadro №6 identificamos la situación más compleja de intervención con respecto a las niñas, niños y adolescentes que habiendo sido víctimas de un delito de violencia por persona de su grupo familiar, tiene adicionalmente la condición de desprotección familiar (sea provisional o permanente) por no contar con ningún/a miembro de su familia que pueda brindarle un entorno protector para resguardarse de futuras agresiones y garantizar su desarrollo integral y, adicionalmente el nivel de afectación a su integridad es mayor, conforme lo definido por la Resolución Ministerial 065-2018-MIMP25.

La desprotección familiar provisional exige que el Estado no sólo brinde atención directa a la niña, niño o adolescente, luego de suspenderse la patria potestad, sino también deberá intervenir con la familia, con la finalidad de erradicar o atenuar los efectos de los factores de riesgo vigentes y suscitar su pronto retorno a su familia de origen. Mientras que la desprotección familiar permanente es una medida severa puesto que implica la pérdida de la patria potestad, y la intervención estatal estará orientada a la promoción de su adopción.

\section{b. Interés Superior del niño}

En el análisis de la tercera estrategia procedemos al análisis de la aplicación del interés superior del niño:

Juicio de Idoneidad (Adecuación): ¿La estrategia implementada produce el cese de la violencia con acciones judiciales sobre el sujeto agresor? ¿La estrategia implementada refiere al retiro de la niña, niño o adolescente de su ámbito familiar, como última ratio, con un carácter temporal o excepcionalmente definitivo?

Juicio de Necesidad: ¿La estrategia implementada se ajusta a la evaluación del riesgo leve, moderado o severo de que el niño, niña o adolescente se vuelva a constituir en víctima? ¿El retiro de su familia de la niña, niño o adolescente es necesaria porque no hay otro mecanismo más efectivo para brindarle protección?.

25 La niña, niño o adolescente presenta lesiones o daños graves en cualquier parte de su cuerpo, así también cuando ha sido expuesto/a a situaciones que ponen en riesgo su vida como consecuencia de la violencia física y así también presentan trastornos mentales como resultado de las lesiones sufridas. 
Juicio de Proporcionalidad: ¿La solución brindada implica la adopción de medidas de judiciales guiada por el criterio de razonabilidad y proporcionalidad?

\section{c. Debida Diligencia}

En esta estrategia se plantean dos intervenciones diferenciadas con medidas de protección judiciales, originadas en el Decreto Supremo №0042020 y en el Decreto Legislativo №1297. En relación a las primeras, el Tribunal Constitucional ha sido enfático en su procedencia y finalidad, sobre el particular esgrime ${ }^{26}$ :

...el propósito perseguido por las medidas de protección es detener la violencia ejercida contra la víctima o prevenir que esta se vuelva a suscitar - de darse otra vez el escenario de violencia, la agresión podría perpetrarse con más intensidad, sobre todo, si existe una denuncia formal de por medio contra el actor ... . para el dictado de las medidas de protección el Juzgado de Familia tomará en cuenta el riesgo al cual se encuentra sometida la vida de la víctima de violencia, la necesidad de protección, así como la urgencia y el peligro en la demora. (Expediente 03378-2019-PA/TC, 2020, párr. 41 y 42)

Sin embargo, no serán suficientes las medidas de protección judiciales del Decreto Supremo 004-2020-MIMP para garantizar que las niñas, niños o adolescentes no vuelvan a ser víctimas, siendo de aplicación complementaria las medidas de desprotección familiar, que consiste prioritariamente en su separación de su familia disfuncional. Sin embargo, es necesario recoger los aportes del Tribunal Constitucional ${ }^{27}$, en relación a la medida de protección de acogimiento residencial, al indicarse que:

...las medidas de protección a favor del menor de edad tienen base normativa ... y son dispuestas con el fin de garantizar el derecho del niño a desarrollarse integralmente en el seno de su familia biológica $\mathrm{y}$, en su defecto, en un ambiente familiar adecuado, tales medidas deben ser tomadas de forma excepcional, teniendo en cuenta el interés superior del niño como norte ineludible y con la debida motivación que la sustente. De lo contrario, se corre el riesgo de cometerse decisiones irrazonables o desproporcionadas. (Sentencia del Tribunal Constitucional Nº 04937-2014-PHC/TC, 2019)

26 Párrafos 41 y 42 del Expediente 03378-2019-PA/TC.

27 Sentencia del Tribunal Constitucional N 04937-2014-PHC/TC. 
En este supuesto cobran especial vigencia los principios jurídicos de diligencia excepcional, a fin que el Estado brinde una respuesta célere y eficaz; razonable y proporcionada, con la finalidad que proceda la selección de la medida más adecuada y para que la valoración del acogimiento residencial sea la excepción y por el plazo más breve; y flexible para la revisión de la medida de protección, buscándose en la niña, niño o adolescente una pronta restitución de su derecho a vivir, crecer y desarrollarse en el seno de su propia familia, o un acogimiento familiar cuando esto no sea viable, a fin de promover para éstos un entorno familiar.

El gran reto de esta estrategia será evitar la revictimización, puesto que la información recogida en las Etapa №1 (Decreto Supremo N $\left.^{\circ} 004-2020\right)$ o en la Etapa №4 (Decreto Legislativo №1297) serán insumos de suma relevancia para la intervención de la UPE.

Por último, es necesario indicar que también podría haber sido a la inversa, hubiera podido comenzar a través de la intervención de la UPE (Decreto Legislativo №1297) y luego ser derivado al juzgado de familia para iniciar el proceso urgente (Decreto Supremo No004-2020-MIMP), esto es aplicable tanto en los Cuadros №5 y №6.

\section{CONCLUSIONES}

1. La articulación normativa de la Ley №30403, Decreto Supremo №004-2020-MIMP, Decreto Legislativo №1297 y sus respectivos reglamentos, favorece a la construcción de estrategias legales a favor de la erradicación de la violencia en agravio de las niñas, niños y adolescentes por integrantes de su grupo familiar.

2. Las niñas, niños y adolescentes que padecen violencia por integrantes de su grupo familiar, serán destinatarios de la condición de "situación de riesgo" o de "desprotección familiar" con las medidas de protección que en cada supuesto corresponda.

3. La intervención en casos de maltrato o violencia en agravio de las niñas, niños y adolescentes deben incorporar distintas estrategias, que favorezcan a la aplicación de medidas de protección judiciales (en aplicación del Decreto Supremo №004-2020-MIMP, Decreto Legislativo №1297 y sus respectivos reglamentos) y medidas de protección sociales (Decreto Legislativo №1297 y su reglamento).

4. La primera estrategia legal refiere a la erradicación de la violencia en agravio de las niñas, niños o adolescentes cuando tiene su origen 
en la falta de competencias parentales para ejercer corrección o disciplina, en dicho supuesto será necesario la adopción de medidas de protección social, para dicho efecto se propone articular la Ley №30403, el Decreto Legislativo №1297 y sus respectivos reglamentos, en lo relativo a situación de riesgo.

5. La segunda estrategia legal refiere a la erradicación de la violencia en agravio de las niñas, niños o adolescentes cuando constituye delito y cuenta con un representante legal para prodigarle cuidado y atención, en dicho supuesto será necesario la adopción de las medidas de protección judiciales para el cese de la violencia y el fortalecimiento de la dinámica familiar con medidas de protección social, para dicho efecto se sugiere la articulación del Decreto Supremo №004-2020-MIMP, el Decreto Legislativo №1297 y su respectivo reglamento, en lo relativo a situación de riesgo.

6. En la tercera estrategia refiere a la erradicación de la violencia en agravio de las niñas, niños o adolescentes cuando constituye delito y no se cuenta con representante legal para prodigarle cuidado y atención, en dicho supuesto será requerido la adopción de las medidas de protección judiciales para el cese de la violencia y el acogimiento familiar o residencial para su protección, para dicho efecto se sugiere la articulación del Decreto Supremo No004-2020MIMP, el Decreto Legislativo №1297 y su respectivo reglamento, en lo relativo a desprotección familiar.

7. El principio jurídico de la familia como institución fundamental para el desarrollo de las personas, favorece a la interpretación y aplicación de las estrategias para conseguir el fortalecimiento de la dinámica familiar y su involucramiento como espacio protector para el cese de violencia. Así también, la posible afectación de la dinámica familiar de origen, de manera temporal o definitiva, cuando existe una probada disfuncionalidad.

8. Elprincipiojurídico del interés superior de la niña, niñoo adolescente, contribuye justificar las estrategias de intervención estatal, mediante la adopción de decisiones motivadas en su idoneidad, necesidad y proporcionalidad.

9. El principio jurídico de la debida diligencia, favorece al contenido de las estrategias legales, mediante la adopción de medidas de protección adecuadas, oportunas, integrales y ejecutables. 


\section{REFERENCIAS}

Barletta, M. (2005). La Finalidad del Proceso Tutelar ¿Probar el estado de abandono o brindar protección?. Revista Diálogo con la Jurisprudencia. $N^{\circ}$ 77. Gaceta Jurídica.

Barletta, M. (2011). Familia y Adolescencia: Búsqueda y Construcción de Procesos Sostenibles de salida al Abandono en la Región Andina. AIBI.

Barletta. M. (2018). Derecho de la Niñez y Adolescencia. Fondo Editorial PUCP.

Comité de Derechos del Niño (2011). Observación General №13 “Derecho el niño a no ser objeto de ninguna forma de violencia" CRC/C/GC/13.

Comité de Derechos del Niño (2006). Observación General №8: “El derecho del niño a la protección contra los castigos corporales y otras formas de castigo crueles o degradantes" CRC/C/GC/8.

Organización Mundial de la Salud (12 de setiembre de 2021). Maltrato. https: / / www.who.int/es / news-room/ fact-sheets/detail/childmaltreatment.

Organización Mundial de la Salud (2002). Informe Mundial sobre la Violencia y la Salud.https://www.who.int/violence_injury_prevention/ violence/world_report/en/abstract_es.pdf

Organización Mundial de la Salud (15 de setiembre del 2021). https:/ /www. who.int/es/news-room/fact-sheets/detail/child-maltreatment

Organización Mundial de la Salud (2009) El Maltrato Infantil. Que hacer y donde obtener evidencias.

http://apps.who.int/iris/bitstream/handle/10665/44228/9789243594361_spa. pdf; isessionid $=653$ B87CEC8257694BE5E8321900AD78A ? sequence $=1$

Sgroi, S., F. Porter y L. Blick (1982). Validation of child sexual abuse, en S. Sgroi (ed.), Handbook of clinical intervention in child sexual abuse, Lexington: Lexington Books.

Reglas de Brasilia sobre Acceso a la Justicia de las Personas en Condición de vulnerabilidad, pobreza y acceso a la justicia (18 de setiembre de 2021) https:/ / capacitacion.jusmisiones.gov.ar/files/material_curso/2019/ Reglas_de_Brasilia_Centro_actualizadas.pdf 
Tribunal Constitucional (2019). Expediente $\mathrm{N}^{\circ}$ 04937-2014-PHC/TC. Sentencia: 15 de enero de 2019 (15 de setiembre de 2021). https:// www.tc.gob.pe/jurisprudencia/2019/04937-2014-HC.pdf

Tribunal Constitucional (2012). Expediente $\mathrm{N}^{\circ}$ 04509-2011-PA/TC. Sentencia:11 de julio de 2012 (15 de setiembre de 2021). https:/ / www. tc.gob.pe/jurisprudencia/2012/04509-2011-AA.html

Tribunal Constitucional (2016) Expediente N02018-2015-PA/TC. Sentencia:19 de octubre de 2016 (15 de setiembre de 2021). https:// tc.gob.pe/jurisprudencia/2018/02018-2015-AA.pdf

Tribunal Constitucional (2020). Expediente 03378-2019-PA/TC. Sentencia: 05 de marzo de 2020 (15 de setiembre de 2021). https://tc.gob.pe/ jurisprudencia/2020/03378-2019-AA.pdf

UNICEF\& Comisión Interamericana de Derechos Humanos (2013). El

Derecho del Niño y la Niña a la Familia. Cuidado alternativo poniendo fin a la institucionalización en las Américas.

Fecha de recepción : 05 de octubre de 2021

Fecha de aceptación : 17 de noviembre de 2021 
